\title{
Association of Lung Function with Serum 25-Hydroxyvitamin D Level according to the Presence of Past Pulmonary Tuberculosis in Korean Adults
}

\author{
Min Sung Kim, Chang-Jin Choi*, Kyung Min Kwon, Kyung-Soo Kim, Whan-Seok Choi, Yoon Jee Oh \\ Department of Family Medicine, Seoul St. Mary's Hospital, College of Medicine, The Catholic University of Korea, Seoul, Korea
}

\begin{abstract}
Background: Vitamin D deficiency is associated with an increased risk of pulmonary tuberculosis (PTB) infection and the treatment outcome. The aim of this study was to examine the relationship between the serum 25-hydroxyvitamin D (25[OH]D) level and lung function in Korean adults according to whether or not there is a history of PTB.

Methods: The data for subjects aged 19 years or older from the Korea National Health and Nutrition Examination Survey 2008-2012 who underwent spirometry, chest radiography, and serum 25(OH)D level measurement were analyzed.

Results: Evidence of past PTB infection was found in 1,482 (9.6\%) of 15,516 subjects. The serum 25(OH)D level was lower in the group with past PTB than in the non-PTB group $(\mathrm{P}=0.013)$. Respiratory dysfunction was more common in the past PTB group than in the non-PTB group (restrictive pattern, $14.0 \%$ vs. 9.6\%; obstructive pattern, $29.6 \%$ vs. $8.2 \%$; both $\mathrm{P}<0.001$ ). After adjusting for age, sex, height, and season, the mean difference in forced expiratory volume in 1 second $\left(\mathrm{FEV}_{1}\right)$ between the highest and lowest quartiles of $25(\mathrm{OH}) \mathrm{D}$ was $100.2 \mathrm{~mL}$ (standard error $=49.3 \mathrm{~mL}$, $\mathrm{P}$ for trend=0.049) in the past $\mathrm{PTB}$ group and $34.7 \mathrm{~mL}$ (standard error=13.6 $\mathrm{mL}, \mathrm{P}=0.009$ ) in the nonPTB group.

Conclusion: $\mathrm{FEV}_{1}$ tended to increase as the vitamin $\mathrm{D}$ quartile increased in both study groups. This relationship was more pronounced in subjects with a history of PTB. A higher serum 25(OH)D level might be beneficial in preserving lung function after PTB infection.
\end{abstract}

Keywords: Mass Chest X-Ray; Spirometry; Lung Function; Tuberculosis; Vitamin D; Korea

Received: July 4, 2017, Revised: August 28, 2017, Accepted: October 12, 2017

*Corresponding Author: Chang-Jin Choi https://orcid.org/0000-0002-1452-0520

Tel: +82-2-2258-1760, Fax: +82-2-2258-2907, E-mail: fmchcj@catholic.ac.kr 


\section{INTRODUCTION}

The incidence of pulmonary tuberculosis (PTB) in South Korea continues to be the highest among the Organization for Economic Cooperation and Development countries. ${ }^{1)}$ In 2016 alone, there were 39,245 patients with PTB undergoing treatment and 30,892 newly diagnosed patients in South Korea. According to the Korea Tuberculosis report from the Korea Centers for Disease Control and Prevention (KCDC), 2,209 individuals died from PTB in 2015. Although the number of deaths is decreasing, PTB remains an important public health problem in South Korea. ${ }^{2)}$

Vitamin D deficiency is associated with an increased risk of PTB infection, ${ }^{3)}$ and an adequate vitamin $\mathrm{D}$ level can lower the risk of relapse of TB. ${ }^{4)}$ It has been reported that serum 25-hydroxyvitamin D $(25[\mathrm{OH}]$ D) levels in persons who have recovered from PTB are consistently lower than the levels in those without a history of PTB. ${ }^{5)}$ Vitamin D plays an important role in the immune response to Mycobacterium tuberculosis by promoting both the formation of phagolysosomes and production of antimicrobial peptides with bactericidal activity and immune-regulating functions. ${ }^{6)}$

Nationwide population studies have shown that there is a positive relationship between the serum 25(OH)D level and lung function. ${ }^{7-9)}$ This association was found to be more prominent in subjects with a history of PTB than in those with asthma or chronic obstructive pulmonary disease (COPD).$^{9)}$ These observations suggest that individuals with vitamin D deficiency are more vulnerable to PTB-induced lung damage. PTB causes structural damage and compromises the vascular system, resulting in permanent scarring that may lead to decreased lung function. Even persons with spontaneously healed PTB and TB scarring on chest radiographs may have impaired lung function. ${ }^{10)}$ Therefore, individuals with a history of past PTB or TB scars on chest radiographs were included in past $\mathrm{PTB}$ group in this study, the aim of which was to examine the relationship between the serum 25(OH)D level and lung function in Korean adults according to the presence of past PTB.

\section{METHODS}

\section{Study Population and Database}

Data were obtained from the Korea National Health and Nutrition Examinations Survey (KNHANES) 2008-2012 conducted by the KCDC. The KNHANES is a cross-sectional survey that is performed every year and is designed to examine the health and nutritional status of the non-institutionalized Korean population. The survey consists of a health interview and nutrition questionnaire. KNHANES uses a multistage cluster probability sampling design to ensure independent and homogeneous sampling for each year in addition to nationally representative sampling.

A total of 17,135 participants aged 19 years or older in KNHANES underwent spirometry. In this study, individuals without a serum 25(OH)D level measurement $(n=789)$ and those with an estimated glomerular filtration rate $<30 \mathrm{~mL} / \mathrm{min}(\mathrm{n}=28)$ were excluded, as were those with findings of active PTB or pulmonary disease other than PTB ( $n=802$ ). Finally, 15,516 individuals were eligible for this study.

All study protocols were approved by the KCDC Institutional Review Board (IRB approval no., 2008-04EXP-01-C, 2009-01CON-03-2C, 2010-02CON-21-C, 2011-02CON-06-C, and 2012-01EXP-01-2C). All subjects volunteered and provided written informed consent prior to participating in this study.

\section{Measurement of Serum 25-Hydroxyvitamin D Level}

A blood sample was obtained from each study subject, refrigerated, transported to the Central Testing Institute, and analyzed within 24 hours. The serum $25(\mathrm{OH}) \mathrm{D}$ concentration was measured using a 25(OH)D radioimmunoassay kit (DiaSorin Inc., Stillwater, MN, USA) with a gamma-counter (1470 Wizard; PerkinElmer Life Sciences Inc., Waltham, MA, USA). To interpret lung function, the serum 25(OH)D levels were divided into four quartiles: Q1 (<15.1 ng/mL), Q2 (15.1$19.1 \mathrm{ng} / \mathrm{mL})$, Q3 (19.1-23.9 ng/mL), and Q4 ( $\geq 23.9 \mathrm{ng} / \mathrm{mL})$ for men, and Q1 (<12.7 ng/mL), Q2 (12.7-16.1 ng/mL), Q3 (16.1-20.5 ng/mL), and Q $4 \geq 20.5 \mathrm{ng} / \mathrm{mL}$ for women.

\section{Pulmonary Function Tests}

Pulmonary function tests were performed using a dry rolling seal spirometer (Model 2130; Sensor-Medics, Yorba Linda, CA, USA). Spirometry was conducted by pulmonary laboratory technicians. The results were transferred to an Internet review center for processing. The data were carefully examined and compared against criteria metrics for acceptability, reproducibility, and quality control. Airflow obstruction was defined as a forced expiratory volume 1 second $\left(\mathrm{FEV}_{1}\right)$ /forced vital capacity (FVC) $<70 \%$ or the lower limit of normal. Restrictive airflow was defined as a reduction in FVC to $<80 \%$ of the predicted value.

\section{Chest Radiographs}

Chest radiographs were taken using a DigiRAD-PG machine (Digirad Corp., Suwanee, GA, USA) installed on an examination vehicle. The presence of non-calcified nodules with distinct margins, calcified nodules, and discrete linear or reticular fibrotic scars with or without calcification were interpreted as PTB scarring. Each chest radiograph was interpreted by two radiologists working independently for the presence of lung disease. Individual readings were compared weekly. Chest radiographs demonstrating PTB-related lesions were re-interpreted by six radiology specialists to confirm the results.

\section{Definition of Past Pulmonary Tuberculosis and Other Variables}

Subjects with a self-reported history of physician-diagnosed PTB or TB scarring on chest radiography were defined as having evidence of past PTB. Household income was divided into high/upper middle and lower middle/low. Heavy drinking was defined as more than seven drinks (for men) or five drinks (for women) on a single day at least twice a week. Regular exercise was defined as engaging in moderate (30 min- 
utes on each occasion at least 3 times per week) or vigorous (20 minutes on each occasion at least 3 times per week) exercise on a regular basis. Education was divided into university/high school graduate (10th grade or higher) and middle school graduate (9th grade and lower).

South Korea is located in a temperate region. Therefore, seasonal variables were adjusted for serum vitamin $\mathrm{D}$ levels with four distinct seasons: spring (March to May), summer (June to August), autumn (September to November), and winter (December to February).

\section{Statistical Analysis}

A sample weight was assigned for participating individuals to produce an unbiased national estimate. Sampling weights were constructed to account for the complex survey design, non-response to the survey, and post-stratification. Continuous variables are expressed as the mean and standard error and categorical variables as the number and percentage. The baseline characteristics, lung function, and serum 25(OH)D levels in the past PTB and non-PTB groups were analyzed

Table 1. Baseline characteristics of the study population $(n=15,516)$

\begin{tabular}{|c|c|c|c|}
\hline Characteristic & $\begin{array}{c}\text { Non-PTB } \\
(n=14,034)\end{array}$ & $\begin{array}{l}\text { Past PTB } \\
(n=1,482)\end{array}$ & P-value \\
\hline \multicolumn{4}{|l|}{ Sex } \\
\hline Male & $6,013(48.3)$ & 847 (60.2) & $<0.001$ \\
\hline Female & $8,021(51.7)$ & $635(39.8)$ & \\
\hline Age (y) & $48.7 \pm 0.2$ & $57.4 \pm 0.5$ & $<0.001$ \\
\hline 19-39 & $1,837(23.5)$ & $70(8.4)$ & $<0.001$ \\
\hline $40-65$ & $9,308(61.0)$ & $851(58.8)$ & \\
\hline$\geq 65$ & $2,889(15.6)$ & $560(32.8)$ & \\
\hline Body mass index $\left(\mathrm{kg} / \mathrm{m}^{2}\right)$ & $24.3 \pm 0.04$ & $23.5 \pm 0.1$ & $<0.001$ \\
\hline$<18.5$ & $217(1.9)$ & $56(4.0)$ & $<0.001$ \\
\hline 18.5 to $<25.0$ & $8,456(59.3)$ & $1,029(68.0)$ & \\
\hline$\geq 25.0$ & $5,361(38.8)$ & $397(28.0)$ & \\
\hline \multicolumn{4}{|l|}{ Smoking } \\
\hline Never & $8,180(53.0)$ & $689(42.5)$ & $<0.001$ \\
\hline Ex-smoker & $2,602(18.5)$ & $428(29.5)$ & \\
\hline Current & $3,089(27.7)$ & $338(27.0)$ & \\
\hline Heavy drinking & $1,615(18.8)$ & $148(18.6)$ & 0.913 \\
\hline Regular exercise & $7,156(50.3)$ & $733(49.7)$ & 0.171 \\
\hline Education (high) & $8,047(64.4)$ & $726(50.4)$ & $<0.001$ \\
\hline Home income (high) & $7,950(57.3)$ & $683(46.7)$ & $<0.001$ \\
\hline \multicolumn{4}{|l|}{ Occupation } \\
\hline Clerical & 4,457 (35.9) & 375 (27.3) & $<0.001$ \\
\hline Manual & $2,869(17.8)$ & $291(18.3)$ & \\
\hline Technical & $1,503(12.3)$ & $145(13.6)$ & \\
\hline Unemployed & $5,043(34.0)$ & 647 (40.8) & \\
\hline \multicolumn{4}{|l|}{ Region } \\
\hline Rural & $3,332(21.4)$ & 341 (21.6) & 0.898 \\
\hline Urban & $10,702(78.6)$ & $1,141(78.4)$ & \\
\hline \multicolumn{4}{|l|}{ Season } \\
\hline Spring & 3,610 (26.3) & 303 (20.8) & $<0.001$ \\
\hline Summer & 3,761 (26.4) & $359(23.0)$ & \\
\hline Autumn & $3,582(25.4)$ & $456(31.2)$ & \\
\hline Winter & $3,081(21.9)$ & 364 (24.9) & \\
\hline
\end{tabular}

Values are presented as frequency (\%) or mean \pm standard error. The data were analyzed using the chi-square test or independent t-test.

PTB, pulmonary tuberculosis. using Student's $t$-test or the chi-square test. The association of $25(\mathrm{OH})$ $\mathrm{D}$ with $\mathrm{FEV}_{1}$ or FVC was modeled by multiple linear regression with the Bonferroni post-hoc test. Deviation of linearity across the quartiles of 25(OH)D levels was assessed by the likelihood test for the quadratic term. All statistical analyses were performed using SAS ver. 9.2 (SAS Institute Inc., Cary, NC, USA). A P-value $<0.05$ was considered statistically significant.

\section{RESULTS}

Evidence of past PTB infection was found in 1,482 (9.6\%) of 15,516 subjects. The baseline characteristics of these subjects are summarized in Table 1. The mean age of the subjects in the past PTB group was higher than that in the non-PTB group (57.4 versus 48.7 years, $\mathrm{P}<0.001)$ and there were more men in the past PTB group than in the non-PTB group ( $60.2 \%$ versus $48.3 \%$ ). The percentage of never-smokers was higher in the non-РTB group and the percentage of eversmokers was higher in the past PTB group.

The past PTB group had a lower $\mathrm{FEV}_{1}, \mathrm{FVC}$, and $\mathrm{FEV}_{1} / \mathrm{FVC}$ ratio (85.3\%, 89.3\%, and 0.73, respectively) than the non-PTB group (93.2\%, $93.7 \%$, and 0.80 ) (Table 2). The proportions of restrictive pattern and

Table 2. Respiratory function in the study population

\begin{tabular}{llll}
\hline \multicolumn{1}{c}{ Variable } & Non-PTB & Past PTB & P-value \\
\hline FEV $_{1}(\mathrm{~L})$ & $2.95 \pm 0.01$ & $2.61 \pm 0.03$ & $<0.001$ \\
FEV $_{1}$ predicted $(\%)$ & $93.2 \pm 0.2$ & $85.3 \pm 0.6$ & $<0.001$ \\
FVC $(\mathrm{L})$ & $3.70 \pm 0.01$ & $3.54 \pm 0.03$ & $<0.001$ \\
FVC predicted $(\%)$ & $93.7 \pm 0.2$ & $89.3 \pm 0.4$ & $<0.001$ \\
FEV $_{1} /$ FVC & $0.80 \pm 0.001$ & $0.73 \pm 0.004$ & $<0.001$ \\
\hline
\end{tabular}

Values are presented as mean \pm standard error. The data were analyzed using Student t-test.

PTB, pulmonary tuberculosis; $\mathrm{FEV}_{1}$, forced expiratory volume in 1 second; FVC, forced vital capacity.

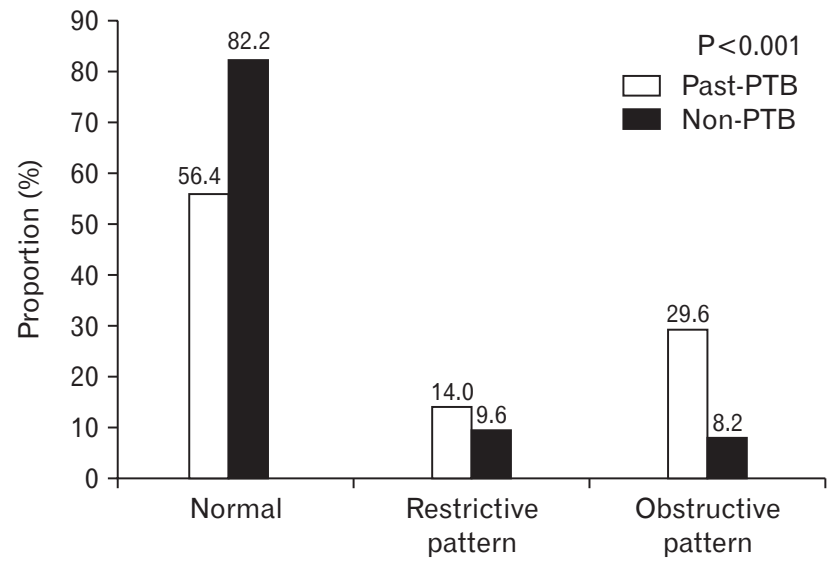

Respiratory dysfunction

Figure 1. Proportion of those with respiratory dysfunction according to history of PTB. The proportion of restrictive pattern and obstructive pattern in the past PTB group was higher than that in the non-PTB group (14.0\% vs. 9.6\% in restrictive pattern and $29.6 \%$ vs. $8.2 \%$ in obstructive pattern, both $\mathrm{P}<0.001$ ). PTB, pulmonary tuberculosis. 
obstructive pattern were higher in the past PTB group than in the nonPTB group (14.0\% versus $9.6 \%$ and $29.6 \%$ versus $8.2 \%$, respectively; both $\mathrm{P}<0.001$ ) (Figure 1).

According to the definition of vitamin D deficiency $(<20 \mathrm{ng} / \mathrm{mL}){ }^{11,12)}$ 92.5\% in the past PTB group and $94.4 \%$ in the non-PTB group were categorized as having an inadequate $25(\mathrm{OH}) \mathrm{D}$ level $(<30 \mathrm{ng} / \mathrm{mL})(\mathrm{Ta}-$ ble 3). There was no significant difference in the distribution of $25(\mathrm{OH})$ $\mathrm{D}$ levels between the two groups. After adjusting for age, sex, season, and body mass index, the 25(OH)D level was lower in the past PTB group than in the non-PTB group.

The mean difference in $\mathrm{FEV}_{1}$ increased in the crude group with increasing 25(OH)D quartile (Q2, Q3, and Q4: 54, 58, and $123 \mathrm{~mL}$ in the past $\mathrm{PTB}$ group, $\mathrm{P}$ for trend $=0.021 ; 20,26$, and $35 \mathrm{~mL}$ in the non-PTB group, $\mathrm{P}$ for trend=0.007). The difference between the top and bottom quartiles of $\mathrm{FEV}_{1}$ was greater in the past PTB group than in the nonPTB group.
After adjusting for age, sex, height, and season, the $\mathrm{FEV}_{1}$ increased in both study groups as the 25(OH)D quartile increased (Table 4$)$. With further adjustment for smoking status, exercise, body mass index, occupation, and region, there was a significant increase in $\mathrm{FEV}_{1}$ in mod-

Table 3. Comparison of serum 25(OH)D levels in the non-PTB and past PTB group

\begin{tabular}{lccc}
\hline \multicolumn{1}{c}{ Variable } & Non-PTB & Past PTB & P-value \\
\hline $25(\mathrm{OH}) \mathrm{D}(\mathrm{ng} / \mathrm{mL})$ & & & 0.105 \\
$<10$ & $844(6.7)$ & $91(6.0)$ & \\
10 to $<20$ & $8,032(57.6)$ & $816(56.8)$ & \\
20 to $<30$ & $4,276(30.1)$ & $453(29.7)$ & \\
$\geq 30$ & $832(5.6)$ & $122(7.4)$ & \\
Mean \pm SE $^{*}$ & $18.49 \pm 0.13$ & $17.90 \pm 0.26$ & 0.013
\end{tabular}

Values are presented as frequency (\%) or mean \pm SE. The data were analyzed using the chi-square test or analysis of covariance.

25(OH)D, 25-hydroxyvitamin D; PTB, pulmonary tuberculosis; SE, standard error. *The vitamin D level was adjusted for age, sex, season, and body mass index.

Table 4. Difference in forced expiratory volume in 1 second by serum 25(OH)D quartile according to evidence of PTB

\begin{tabular}{|c|c|c|c|c|c|}
\hline \multirow{2}{*}{ Variable } & \multicolumn{4}{|c|}{ 25(OH)D quartile } & \multirow{2}{*}{$P$ for tren } \\
\hline & Q1 & Q2 & Q3 & Q4 & \\
\hline \multicolumn{6}{|l|}{ Non-PTB (mL) } \\
\hline Crude & Ref & $20.0 \pm 13.0$ & $26.0 \pm 13.0$ & $35.0 \pm 13.0^{*}$ & 0.007 \\
\hline Model 1 & Ref & $22.3 \pm 13.8$ & $28.3 \pm 13.6^{*}$ & $34.7 \pm 13.6^{*}$ & 0.009 \\
\hline Model 2 & Ref & $20.6 \pm 13.8$ & $25.6 \pm 13.5$ & $32.8 \pm 13.5^{\star}$ & 0.013 \\
\hline Model 3 & Ref & $17.5 \pm 13.6$ & $23.6 \pm 13.4$ & $33.0 \pm 13.5^{\star}$ & 0.012 \\
\hline \multicolumn{6}{|l|}{ Past PTB (mL) } \\
\hline Crude & Ref & $54.0 \pm 48.0$ & $58.0 \pm 49.0$ & $123.0 \pm 51.0$ & 0.021 \\
\hline Model 1 & Ref & $39.8 \pm 48.5$ & $43.9 \pm 47.2$ & $100.2 \pm 49.3^{*}$ & 0.049 \\
\hline Model 2 & Ref & $40.0 \pm 48.5$ & $42.8 \pm 47.2$ & $97.7 \pm 48.8^{\star}$ & 0.054 \\
\hline Model 3 & Ref & $36.0 \pm 48.4$ & $46.5 \pm 47.5$ & $120.1 \pm 50.6^{*}$ & 0.020 \\
\hline
\end{tabular}

Values are presented as the mean \pm standard error. The data were analyzed by multiple linear regression with the Bonferroni post-hoc test. Model 1 was adjusted for age, sex, height, and season; model 2 was adjusted for the same variables as in model 1 with additional adjustment for smoking and exercise; model 3 was adjusted for the same variables as in model 2 with additional adjustment for body mass index, occupation, and region. Q1, <15.1 ng/mL; Q2, 15.1-19.1 ng/mL; Q3, 19.1-23.9 ng/mL; and Q4, $\geq 23.9 \mathrm{ng} / \mathrm{mL}$ for men. Q1, <12.7 ng/mL; Q2, 12.7-16.1 ng/mL; Q3, 16.1-20.5 ng/mL; and Q4, $\geq 20.5 \mathrm{ng} / \mathrm{mL}$ for women.

25(OH)D, 25-hydroxyvitamin D; PTB, pulmonary tuberculosis; Q, quartile; Ref, reference.

${ }^{*} \mathrm{P}<0.05$, compared with the lowest vitamin $\mathrm{D}$ quartile (Q1).

Table 5. Difference in forced vital capacity by serum 25(OH)D quartile according to evidence of PTB

\begin{tabular}{|c|c|c|c|c|c|}
\hline \multirow{2}{*}{ Variable } & \multicolumn{4}{|c|}{ 25(OH)D (quartile) } & \multirow{2}{*}{ P for trenc } \\
\hline & Q1 & Q2 & Q3 & Q4 & \\
\hline \multicolumn{6}{|c|}{ Non-PTB (mL) } \\
\hline Crude & Ref & $22.0 \pm 16.0$ & $24.0 \pm 16.0$ & $38.0 \pm 16.0$ & 0.122 \\
\hline Model 1 & Ref & $20.4 \pm 16.2$ & $25.2 \pm 15.8$ & $39.6 \pm 16.2^{*}$ & 0.015 \\
\hline Model 2 & Ref & $20.5 \pm 16.2$ & $25.1 \pm 15.7$ & $39.4 \pm 16.2^{*}$ & 0.016 \\
\hline Model 3 & Ref & $15.4 \pm 16.1$ & $19.5 \pm 15.7$ & $31.2 \pm 16.0$ & 0.052 \\
\hline \multicolumn{6}{|c|}{ Past PTB (mL) } \\
\hline Crude & Ref & $75.0 \pm 46.0$ & $66.0 \pm 45.0$ & $88.0 \pm 48.0$ & 0.502 \\
\hline Model 1 & Ref & $62.0 \pm 45.8$ & $48.5 \pm 44.3$ & $69.3 \pm 47.7$ & 0.203 \\
\hline Model 2 & Ref & $61.2 \pm 45.8$ & $51.7 \pm 44.4$ & $69.4 \pm 47.0$ & 0.186 \\
\hline Model 3 & Ref & $55.2 \pm 45.1$ & $53.2 \pm 44.4$ & $73.3 \pm 46.1$ & 0.141 \\
\hline
\end{tabular}

Values are presented as the mean \pm standard error. Model 1 was adjusted for age, sex, height, and season; model 2 was adjusted for the same variables as in model 1 with additional adjustment for smoking and exercise; model 3 was adjusted for the same variables as in model 2 with additional adjustment for body mass index, occupation, and region. Q1, <15.1 ng/mL; Q2, 15.1-19.1 ng/mL; Q3, 19.1-23.9 ng/mL; and Q4, $\geq 23.9 \mathrm{ng} / \mathrm{mL}$ for men. Q1, <12.7 ng/mL; Q2, 12.7-16.1 ng/mL; Q3, 16.1-20.5 ng/mL; and Q4, $\geq 20.5 \mathrm{ng} / \mathrm{mL}$ for women. The data were analyzed by multiple linear regression with the Bonferroni post-hoc test and are shown as the mean and standard error in $\mathrm{mL}$. 25(OH)D, 25-hydroxyvitamin D; PTB, pulmonary tuberculosis; Q, quartile; Ref, reference.

${ }^{*} P<0.05$, compared with the lowest vitamin D quartile (Q1). 
els 2 and 3 (Table 4). In the non-PTB group, there was a positive association between FVC and the serum 25(OH)D quartiles in models 1 and 2 (Table 5).

\section{DISCUSSION}

In this study, individuals with past PTB had worse pulmonary function $\left(\mathrm{FEV}_{1}, \mathrm{FVC}, \mathrm{FEV}_{1} / \mathrm{FVC}\right.$ ratio) and lower 25(OH)D levels than those without a history of $\mathrm{PTB} . \mathrm{FEV}_{1}$ tended to increase with increasing $25(\mathrm{OH}) \mathrm{D}$ quartile. The difference in the $25(\mathrm{OH}) \mathrm{D}$ level between the highest and lowest quartiles for $\mathrm{FEV}_{1}$ was greater in the group with past PTB than in the group without past $\mathrm{Tb}(123 \mathrm{~mL}$ versus $35 \mathrm{~mL})$. This finding indicates that lung function was more influenced by the serum 25(OH)D level in the past PTB group than in the non-PTB group.

A positive relationship between the serum 25(OH)D level and lung function has been reported by several nationwide population studies. According to a National Health and Nutrition Examination Survey in the United States, the mean difference in $\mathrm{FEV}_{1}$ between the top and bottom quintiles of serum 25(OH)D was $126 \mathrm{~mL}(\mathrm{P}<0.0001) .{ }^{9)}$ Crosssectional data obtained from a nationwide cohort in the United Kingdom revealed a linear relationship between the 25(OH)D level and lung function in that the $\mathrm{FEV}_{1}$ value was $8 \mathrm{~mL}$ higher in volume for each $4 \mathrm{ng} / \mathrm{mL}$ of increase in the $25(\mathrm{OH}) \mathrm{D}$ level. ${ }^{7)}$ A positive relationship between the serum 25(OH)D level and lung function has also been confirmed in the Korean population. ${ }^{9)}$

Vitamin D deficiency is a risk factor for PTB because of its essential role in the immune system. ${ }^{13)}$ Vitamin D appears to play a part in innate immunity via the nuclear vitamin $\mathrm{D}$ receptor (VDR). Activation of the VDR induces production of cathelicidin antimicrobial peptide from macrophages and epithelial cells, thereby enhancing autophagy in monocytes in response to the antimicrobial effect of cathelicidin. ${ }^{14)}$ Vitamin D also plays a role in acquired immunity by inhibiting induction of apoptosis in activated B-cells and modulating proliferation of $\mathrm{T}$ lymphocytes. ${ }^{15)}$ The number of candidate VDR polymorphisms has been found to be associated with susceptibility to PTB. ${ }^{16)}$ Vitamin D deficiency is associated with decreased lung function. ${ }^{17-19)}$ Vitamin D also inhibits formation of matrix metalloproteinase-9 (MMP-9), ${ }^{20)}$ thereby influencing degradation of tissue remodeling in the lung parenchyma. In addition, vitamin D suppresses inflammation in the airways by reducing the production of inflammatory cytokines and chemokines by epithelial cells. ${ }^{21)}$

The results of the present study are similar to those of a meta-analysis that found the $25(\mathrm{OH}) \mathrm{D}$ level to be lower in individuals with PTB. ${ }^{3)}$ Moreover, the vitamin D level has been reported to remain consistently low even after treatment of PTB. ${ }^{5)}$ Patients with vitamin D insufficiency $(<30 \mathrm{ng} / \mathrm{mL})$ tend to have a higher likelihood of recurrence of $\mathrm{PTB},{ }^{4)}$ which results in more impairment of lung function because of the residual damage to lung tissue. ${ }^{22)}$ Furthermore, vitamin D deficiency plays a role in the development of COPD with increased MMP-9 level, ${ }^{23)}$ thus increasing the risk of COPD and decreasing lung function in the past PTB group with low 25(OH)D level. In the population- based Burden of Obstructive Lung Disease study, a history of PTB was associated with both airflow obstruction and spirometric restriction. ${ }^{24)}$

Randomized clinical trials have yielded inconsistent results with regard to the efficacy of vitamin D supplementation for PTB. In an Indonesian study, negative sputum conversion with radiographic improvement was achieved in $100 \%$ of 67 patients supplemented with vitamin D $0.25 \mathrm{mg} / \mathrm{d}$, whereas only $78.7 \%$ of those who received placebo showed negative sputum conversion. ${ }^{25)}$ However, a clinical trial in India found no significant difference in sputum culture conversion time between a vitamin $\mathrm{D}$ supplementation group and a placebo group. ${ }^{26)}$ The reasons for these inconsistent results are unclear. One possible explanation is that the optimal vitamin D concentration for respiratory health is as yet unknown. Another explanation may lie in the various genetic polymorphisms of the VDR. One randomized clinical trial of vitamin D supplementation found clinical and radiographic improvement in patients with TB and vitamin D deficiency; ${ }^{27)}$ however, another study found that the sputum culture conversion time was only shortened in individuals with the $t$ genotype of TaqI VDR polymorphism. ${ }^{28)}$ Further studies are needed to identify the benefits of vitamin D supplementation according to VDR polymorphism in subjects with PTB.

A previous Korean report demonstrated that a significant number of people who did not report a history of PTB had evidence of TB scars on chest radiographs (i.e., spontaneously healed PTB). ${ }^{29)}$ A prospective cohort study that investigated subjects with spontaneously healed PTB and normal subjects over a 10-year period found a greater decrease in predicted $\mathrm{FEV}_{1}$ in those with spontaneously healed PTB. ${ }^{10)}$ Excluding individuals with TB lesions on chest radiography may underestimate the association between $\mathrm{TB}$ and respiratory dysfunction. ${ }^{30)}$

This research has several limitations. First, the study had a crosssectional design, so reverse causality as an explanation for the observed association could not be ruled out. Second, the severity of PTBinduced lung damage and the presence of recurrence could not be determined because this information is not available in KHANES. Third, the self-reported history of the study participants did not contain information on vitamin $\mathrm{D}$ supplementation or medication that might affect the serum 25(OH)D level.

In conclusion, we have found a tendency for $\mathrm{FEV}_{1}$ to increase with increasing vitamin $\mathrm{D}$ level regardless of whether or not there is a history of PTB. In this study, the increase in $\mathrm{FEV}_{1}$ was greater for the higher vitamin D quartiles, especially Q4 in the group with past PTB. These results suggest that a higher 25(OH)D level may have a beneficial role in preserving lung function after PTB infection. Further studies are needed to identify the optimal vitamin D concentration for respiratory health.

\section{CONFLICT OF INTEREST}

No potential conflict of interest relevant to this article was reported.

\section{ACKNOWLEDGMENTS}

The statistical analysis in this study was supported by a grant 
(HI14C1731) from the Korea Health Technology R\&D Project through the Korea Health Industry Development Institute funded by the Ministry of Health \& Welfare, Korea.

\section{ORCID}

Min Sung Kim: https://orcid.org/0000-0002-3536-3093

Chang-Jin Choi: https://orcid.org/0000-0002-1452-0520

Kyung Min Kwon: https://orcid.org/0000-0002-6298-8507

Kyung-Soo Kim: https://orcid.org/0000-0003-3501-1212

Whan-Seok Choi: https://orcid.org/0000-0001-8978-9885

Yoon Jee Oh: https://orcid.org/0000-0002-8499-7084

\section{REFERENCES}

1. Kim JH, Yim JJ. Achievements in and challenges of tuberculosis control in South Korea. Emerg Infect Dis 2015;21:1913-20.

2. Korea Centers for Disease Control and Prevention. Annual report on the notified tuberculosis in Korea. Cheongju: Korea Centers for Disease Control and Prevention; 2017.

3. Nnoaham KE, Clarke A. Low serum vitamin D levels and tuberculosis: a systematic review and meta-analysis. Int J Epidemiol 2008;37:113-9.

4. Mehta S, Mugusi FM, Bosch RJ, Aboud S, Urassa W, Villamor E, et al. Vitamin D status and TB treatment outcomes in adult patients in Tanzania: a cohort study. BMJ Open 2013;3:e003703.

5. Kim JH, Park JS, Cho YJ, Yoon HI, Song JH, Lee CT, et al. Low serum 25-hydroxyvitamin D level: an independent risk factor for tuberculosis? Clin Nutr 2014;33:1081-6.

6. Schwalfenberg GK. A review of the critical role of vitamin D in the functioning of the immune system and the clinical implications of vitamin D deficiency. Mol Nutr Food Res 2011;55:96-108.

7. Berry DJ, Hesketh K, Power C, Hypponen E. Vitamin D status has a linear association with seasonal infections and lung function in British adults. Br J Nutr 2011;106:1433-40.

8. Black PN, Scragg R. Relationship between serum 25-hydroxyvitamin d and pulmonary function in the third national health and nutrition examination survey. Chest 2005;128:3792-8.

9. Choi CJ, Seo M, Choi WS, Kim KS, Youn SA, Lindsey T, et al. Relationship between serum 25-hydroxyvitamin D and lung function among Korean adults in Korea National Health and Nutrition Examination Survey (KNHANES), 2008-2010. J Clin Endocrinol Metab 2013;98: 1703-10.

10. Lee SH, Kwon AM, Yang HC, Lee SK, Kim Y, Choi JH, et al. Longitudinal lung function decrease in subjects with spontaneous healed pulmonary tuberculosis. PLoS One 2016;11:e0164039.

11. Rosen CJ. Clinical practice: vitamin D insufficiency. N Engl J Med 2011;364:248-54.

12. Holick MF, Chen TC. Vitamin D deficiency: a worldwide problem with health consequences. Am J Clin Nutr 2008;87:1080S-6S.

13. Liu PT, Stenger S, Tang DH, Modlin RL. Cutting edge: vitamin D-mediated human antimicrobial activity against Mycobacterium tuberculosis is dependent on the induction of cathelicidin. J Immunol 2007;179: 2060-3.

14. Yuk JM, Shin DM, Lee HM, Yang CS, Jin HS, Kim KK, et al. Vitamin D3 induces autophagy in human monocytes/macrophages via cathelicidin. Cell Host Microbe 2009;6:231-43.

15. Chen S, Sims GP, Chen XX, Gu YY, Chen S, Lipsky PE. Modulatory effects of 1,25-dihydroxyvitamin D3 on human B cell differentiation. J Immunol 2007;179:1634-47.

16. Leandro AC, Rocha MA, Cardoso CS, Bonecini-Almeida MG. Genetic polymorphisms in vitamin D receptor, vitamin D-binding protein, Toll-like receptor 2, nitric oxide synthase 2 , and interferon-gamma genes and its association with susceptibility to tuberculosis. Braz J Med Biol Res 2009;42:312-22.

17. Yumrutepe T, Aytemur ZA, Baysal O, Taskapan H, Taskapan CM, Hacievliyagil SS. Relationship between vitamin D and lung function, physical performance and balance on patients with stage I-III chronic obstructive pulmonary disease. Rev Assoc Med Bras (1992) 2015;61: $132-8$.

18. Hagaman JT, Panos RJ, McCormack FX, Thakar CV, Wikenheiser-Brokamp KA, Shipley RT, et al. Vitamin D deficiency and reduced lung function in connective tissue-associated interstitial lung diseases. Chest 2011;139:353-60.

19. Zosky GR, Berry LJ, Elliot JG, James AL, Gorman S, Hart PH. Vitamin D deficiency causes deficits in lung function and alters lung structure. Am J Respir Crit Care Med 2011;183:1336-43.

20. Boyan BD, Wong KL, Fang M, Schwartz Z. 1alpha,25(OH)2D3 is an autocrine regulator of extracellular matrix turnover and growth factor release via ERp60 activated matrix vesicle metalloproteinases. J Steroid Biochem Mol Biol 2007;103:467-72.

21. Hansdottir S, Monick MM, Lovan N, Powers L, Gerke A, Hunninghake GW. Vitamin D decreases respiratory syncytial virus induction of NFkappaB-linked chemokines and cytokines in airway epithelium while maintaining the antiviral state. J Immunol 2010;184:965-74.

22. Hnizdo E, Singh T, Churchyard G. Chronic pulmonary function impairment caused by initial and recurrent pulmonary tuberculosis following treatment. Thorax 2000;55:32-8.

23. Herr C, Greulich T, Koczulla RA, Meyer S, Zakharkina T, Branscheidt $\mathrm{M}$, et al. The role of vitamin D in pulmonary disease: COPD, asthma, infection, and cancer. Respir Res 2011;12:31.

24. Amaral AF, Coton S, Kato B, Tan WC, Studnicka M, Janson C, et al. Tuberculosis associates with both airflow obstruction and low lung function: BOLD results. Eur Respir J 2015;46:1104-12.

25. Nursyam EW, Amin Z, Rumende CM. The effect of vitamin D as supplementary treatment in patients with moderately advanced pulmonary tuberculous lesion. Acta Med Indones 2006;38:3-5.

26. Daley P, Jagannathan V, John KR, Sarojini J, Latha A, Vieth R, et al. Adjunctive vitamin $\mathrm{D}$ for treatment of active tuberculosis in India: a randomised, double-blind, placebo-controlled trial. Lancet Infect Dis 2015;15:528-34.

27. Salahuddin N, Ali F, Hasan Z, Rao N, Aqeel M, Mahmood F. Vitamin D accelerates clinical recovery from tuberculosis: results of the SUCCINCT Study [Supplementary Cholecalciferol in recovery from tuberculosis]: a randomized, placebo-controlled, clinical trial of vitamin D supplementation in patients with pulmonary tuberculosis. BMC Infect Dis 2013;13:22.

28. Martineau AR, Timms PM, Bothamley GH, Hanifa Y, Islam K, Claxton AP, et al. High-dose vitamin D(3) during intensive-phase antimicrobial treatment of pulmonary tuberculosis: a double-blind randomised 
controlled trial. Lancet 2011;377:242-50.

29. Lee D. Annual report on the notified tuberculosis patients in Korea. Cheongju: Korea Centers for Disease Control and Prevention; 2013.

30. Choi CJ, Choi WS, Lee SY, Kim KS. The definition of past tuberculosis affects the magnitude of association between pulmonary tuberculosis and respiratory dysfunction: Korea National Health and Nutrition Examination Survey, 2008-2012. J Korean Med Sci 2017;32:789-95. 